\title{
Atividade do óleo essêncial de orégano contra fungos patogênicos do arroz: crescimentos micelial em placas.
}

Zanandrea, I.*; Juliano D. S.; Andréa, B. M.; Juliane, L.; Veridiana K. B.

Universidade Federal de Pelotas

Departamento de Agronomia

\section{Resumo}

O objetivo deste trabalho foi testar o efeito do óleo essencial de Origanum vulgare L. sobre o crescimento micelial de fungos patogênicos do arroz. Discos de micélio dos fungos Alternaria sp., Bipolaris oryzae, Curvularia sp., Gerlachia oryzae, Rhizoctonia solani e Sclerotinia sclerotiorum foram colocados no centro de placas de Petry com BDA e óleo em diferentes concentrações: óleo puro, $1: 2,1: 4,1: 8,1: 16,1: 32$ as quais foram incubadas a $22 \pm 2^{\circ} \mathrm{C}$ sob fotoperíodo de $12 \mathrm{~h}$, utilizando-se para controle placas com Batata-Dextrose-Ágar + etanol. O crescimento foi medido assim que o micélio controle preenchesse toda a placa. Todos os fungos apresentaram redução do crescimento micelial. B. oryzae foi o mais sensível, com diferença estatística em todas as concentrações.

\section{Abstract}

The purpose of this study was test the effect of the Origanum vulgare essential oil on the micelial growth of the rice pathogenic fungi. Micelium discs of the fungi Alternaria sp., Bipolaris oryzae, Curvularia sp., Gerlachia oryzae, Rhizoctonia solani and Sclerotinia sclerotiorum were placed in the center of Petry plates with PDA and oil in different concentrations: pure oil, 1:2, 1:4, 1:8, 1:16, 1:32 which was incubated to $22 \pm 2{ }^{\circ} \mathrm{C}$ under $12 \mathrm{~h}$ photoperiod, until the control (Potato-Dextrose-Agar + ethanol) fill all the plate. All genera showed reduction in the micelial growth. B. oryzae was the most sensible, with statistic difference in all concentrations.

O uso intensivo e indiscriminado de agrotóxicos tem causado diversos problemas ao meio ambiente. Visando minimizar os efeitos negativos do uso dessas substâncias e aumentar a produção de alimentos de melhor qualidade, propiciando assim o desenvolvimento de uma agricultura "mais limpa", têm-se buscado novas medidas de proteção das plantas contra as doenças.

A utilização de substâncias extraídas de vegetais que podem atuar na inibição de fungos fitopatogênicos pode ser uma opção no controle de doenças no campo ${ }^{1}$. Relatos têm demonstrado a eficiência de óleos de plantas medicinais na inibição do crescimento de fungos ${ }^{2,3,4}$.

O orégano (Origanum vulgare L.) é uma planta da 
família Lamiaceae, herbácea, muito ramificada, utilizada como condimento ${ }^{5}$ e medicinalmente, sendo-lhe atribuídas diversas indicações, tais como, dentre outras, antibacteriano, antifúngico, antiinflamatório, antioxidante, anticancerígeno, emoliente e digestivo ${ }^{6}$. Todas essas características são atribuídas ao carvacrol, composto químico considerado principal pela sua abundância.

Este trabalho objetivou testar a ação de óleos essenciais da folha de orégano, obtidos por arraste a vapor, no crescimento do micélio de fungos patogênicos do arroz.

Todos os fungos testados tiveram o crescimento micelial reduzido pela presença do óleo no meio de cultura, quando comparado ao meio sem adição deste (BDA), comprovando sua ação (Tabela 1), uma vez que o diluente utilizado (etanol) não influenciou o crescimento dos fungos. Houve diferença estatística quanto à eficiência do óleo nas diferentes concentrações. B. oryzae foi o fungo mais sensível, pois apresentou diferença estatística para todas as diluições testadas, sendo que óleo puro mostrou uma diferença de $98 \%$ em relação ao controle. Para este fungo, óleo puro apresentou maior diferença quando comparado às diluições 1:2, 1:4 e 1:8, e estes foram maiores que 1:16 e 1:32. A concentração óleo puro para fungo Curvularia $s p$. mostrou maior diferença estatística que 1:4, e os fungos $G$. oryzae e Alternaria $s p$. apresentaram maior diferença da diluição óleo puro em relação à diluição1:16.

Tabela 1: Diâmetro médio ( $\mathrm{mm}$ ) de crescimento fúngico em meio BDA (Batata-Dextrose-Ágar) contendo diferentes concentrações de óleo de orégano.

\begin{tabular}{c|c|c|c|c|c|c}
\hline Diluição & Alternaria sp. & B. oryzae & Curvularia sp. & G. oryzae & R. solani & S. sclerotiorum \\
\hline BDA & 87,1 & 85,1 & 89,0 & 89,0 & 89,0 & 89,0 \\
\hline Etanol & 85,0 & 75,6 & 89,0 & 88,5 & 89,0 & 89,0 \\
\hline Óleo puro & $41,9 *$ & $16,5 *$ & $10,5 *$ & $34,8 *$ & $9,8 *$ & $55,2 *$ \\
\hline $1: 2$ & 67,8 & $50,5 *$ & 89,0 & 81,3 & 89,0 & 89,0 \\
\hline $1: 4$ & 72,1 & $54,0 *$ & $26,5 *$ & 81,9 & $15,8 *$ & $71,8 *$ \\
\hline $1: 8$ & 67,1 & $56,7 *$ & 89,0 & 80,5 & 78,5 & 89,0 \\
\hline $1: 16$ & $65,5 *$ & $60,3 *$ & 89,0 & $76,5 *$ & 68,8 & 89,0 \\
\hline $1: 32$ & 73,0 & $63,0 *$ & 89,0 & 82,9 & 89,0 & \\
\hline
\end{tabular}

* Diferença significativa versus BDA - teste de Duncan (5\%).

ZANANDREA et al. ${ }^{7}$ e SANTOS et al. ${ }^{8}$ também testaram o efeito do óleo de orégano contra fungos patogênicos ao arroz utilizando duas metodologias diferentes, verificando o crescimento em meio líquido e em placas sobrepostas, respectivamente. Os resultados foram semelhantes aos obtidos neste trabalho, independente da metodologia utilizada.

Resultados relevantes obtidos pelo uso de óleos vegetais no controle de fungos, utilizando metodologias semelhantes à deste trabalho, estão sendo alcançados. FIORI et al. ${ }^{2}$ comprovaram a eficácia do óleo essencial de Achillea millefolium, Cymbopogon citratus, Eucalyptus citriodora e Ageratum conyzoides sobre o crescimento micelial do fungo Didymella bryoniae. Da mesma forma, MELLO \& AMORIM $^{9}$ testaram o óleo de Azadirachta indica contra o crescimento de Colletotrichum gloeosporioides e observaram que independentemente da concentração do óleo utilizado ocorreu inibição do crescimento micelial quando comparado com o tratamento sem a adição do produto ao meio.

SALGADO et al. ${ }^{10}$ testaram a atividade fungitóxica de óleo de três espécies de eucalipto sobre Fusarium oxysporum, Botrytis cinerea e Bipolaris sorokiniana e obtiveram variadas inibições no crescimento micelial em todas as espécies para diferentes concentrações de óleo; no entanto, o óleo com maior ação fungitóxica foi de Eucalyptus urophylla, sendo essa atribuída à presença do composto globulol, não detectado nos óleos de E. citriodora e $E$. camaldulensis.

\section{Material e métodos}

Para este experimento foi utilizado óleo puro e nas concentrações: 1:2, 1:4, 1:8, 1:16, 1:32. Como controle, foram utilizados BDA (Batata-Dextrose-Ágar) + Etanol (diluente) e BDA. Alíquotas de óleo (10 $\mu \mathrm{l} / 10 \mathrm{ml}$ de meio) foram adicionadas ao meio BDA fundente vertido em placas de Petri. No centro de cada placa, após a solidificação do meio, foi colocado um disco de micélio dos fungos Alternaria sp., B. oryzae, Curvularia sp., G. oryzae, R. solani e $S$. sclerotiorum, previamente crescidos em BDA, individualmente, sendo as placas incubadas a $22 \pm 2^{\circ} \mathrm{C}$ sob fotoperíodo de 12 horas. A avaliação foi realizada através de duas medições diametralmente opostas das colônias quando o controle (BDA) atingiu o máximo de crescimento. $\mathrm{O}$ experimento foi realizado em 4 repetições de forma inteiramente casualizada e os resultados submetidos a teste de média (Duncan a 5\%).

\section{Referências}

${ }^{1}$ Coutinho WM, Araujo E, Magalhães FHL. Efeitos de extratos de plantas anacardiáceas e dos fungicidas químicos Benomyl e Captan sobre a microflora e qualidade fisiológica de feijoeiro (Phaseolus vulgaris L.). Ciência e Agrotécnica 
1999; 23: 560-68.

${ }^{2}$ Fiori ACG, Schwan-Estrada KRF, Stangarlin JR, Vida JB, Scapimca, Cruz MES, Pascholati SF. Antifungal activity of leaf exctracts and essential oils of some medicinal plants against Didymella bryoniae. Journal of Phytopathology 2000; 148: 483-87.

${ }^{3}$ Alves ESS, Santos MP, Santos RB, Venturaja, Fernandes PMB. Eficiência de óleos essenciais no controle "in vitro" da germinação de conídios e do crescimento micelial de Colletotrichum musae. Fitopatologia Brasileira 2002 (suplemento); 27: 75.

${ }^{4}$ Soliman KM, Badeaa RI. Effect of oil extracted from some medicinal plants on different mycotoxigenic fungi. Food and Chemical Toxicology, 40: 1669-675, 2002.

${ }^{5}$ Joly AB. Botânica: Introdução à Taxonomia Vegetal. $12^{\mathrm{a}}$ ed. São Paulo. Companhia Editora Nacional, 1998, 777p.

${ }^{6}$ Lorenzi H, Matos FJA. Plantas medicinais no Brasil: nativas e exóticas cultivadas. Ed:Nova Odessa, São Paulo. Instituto Plantarum, 2002. 512p.

${ }^{7}$ Zanandreia I, Santos J, Ludwig J, Bosenbecker VK, Bobrowski VL, Moura AB. Atividade antifúngica do óleo essencial de orégano (Origanum vulgare L.) testado contra fungos patogênicos do arroz. III - crescimento micelial de fungos em meio líquido. 55 Congresso Nacional de Botânica (CD).

${ }^{8}$ Santos J, Zanandrea I, Ludwig J, Bosenbecker VK, Boborowski VL, Moura AB. Atividade antifúngica do óleo essencial de orégano (Origanum vulgare L.) testado contra fungos patogênicos do arroz. IV - crescimento micelial de fungos em placas sobrepostas. Fitopatologia Brasileira 2004 (suplemento); 29: 200-01.

${ }^{9}$ Mello ASF, Amorim L. Comportamento in vitro de Colletotrichum gloeosporioides na presença de óleo de nim. Fitopatologia Brasileira 2004 (suplemento); 29: 130-31.

${ }^{10}$ Salgado APSP, Cardoso MG, Souza PE, Souza JA, Abreu CMP, Pinto JEBP. Avaliação da atividade fungitóxica de óleos essenciais de folhas de Eucalyptus sobre Fusarium oxysporum, Botrytis cinerea e Bipolaris sorokiniana. Ciênc. Agrotéc., Lavras, v. 27, n.2, p. 249-254, 2003.

\section{Autora para correspondência}

Ilisandra Zanandrea

Rua São Manoel, 375, Bairro Santa Terezinha

Pelotas, RS, Brasil, CEP 96065-530

e-mail: dandajs@ universiabrasil.net 